\title{
Uma perspectiva semiótica para a comunicação aumentativa e alternativa (CAA): análise de um aplicativo assistivo.
}

A semiotic perspective for augmentative and alternative communication (AAC): analysis of an assistive application.

SOARES, Kamyla Lemes. Mestranda - Universidade do Estado de Santa Catarina - UDESC

kamylalemessoares@gmail.com

SCÓZ, Murilo. Doutor - Universidade do Estado de Santa Catarina - UDESC

muriloscoz@gmail.com

MAGER, Gabriela Botelho. Doutora - Universidade do Estado de Santa Catarina - UDESC

gabriela.mager@udesc.br

\section{Resumo}

O artigo propõe uma análise semiótica de um aplicativo de comunicação aumentativa e alternativa que torne possível a comunicação de pessoas não falantes. O estudo terá como base uma das teorias semiótica francesa, a Greimasiana, levando em consideração o conceito da biplanaridade da linguagem e a articulação entre os planos de expressão e de conteúdo. A partir desta perspectiva teórica, desenvolve-se uma análise das dinâmicas de uso de um sistema baseado em tecnologias de comunicação aumentativa, considerando a construção e a funcionalidade das categorias e pictogramas, dos atalhos de respostas rápidas e do sistema de localização do usuário e interação, a partir das categorias propostas pela semiótica plástica. 0 estudo demonstra o alinhamento dos elementos da expressão do sistema a operações acionadas pelo usuário, permitindo reconhecer as possibilidades do modelo greimasiano para o aprimoramento da usabilidade, da dinamicidade da interação e da eficiência semiótica de sistemas interativos.

Palavras Chave: Semiótica; Tecnologia assistiva; Comunicação aumentativa e alternativa;.

\section{Abstract}

The article proposes a semiotic analysis of an augmentative and alternative communication application that makes possible the communication of non-speaking people. The study will be based on the French or Greimasian semiotic theory, taking into account the concept of biplanarity of language and the articulation between the planes of expression and content. From this theoretical perspective, an analysis of the dynamics of the use of a system based on augmentative communication technologies is developed, considering the construction and functionality of the categories and pictograms, the quick response shortcuts and the user localization system and interaction, from the categories proposed by the plastic semiotics. The study demonstrates the alignment of the elements of the expression of the system with operations driven by the user, allowing to recognize the possibilities of the greimasiano model for the improvement of the usability, the dynamics of the interaction and the semiotic efficiency of interactive systems. 
Keywords: Semiotics; Assistive technology; Augmentative and alternative communication.

\section{INTRODUÇÃO}

$\mathrm{Na}$ vida social, as pessoas empregam diversos meios de comunicação para diferentes finalidades, como a fala, a escrita, LIBRAS (língua brasileira de sinais), gestos, vestimentas, dentre outras. Entretanto, em circunstâncias específicas, certas condições (físicas, patológicas, sociais, psicológicas, anatômicas e mesmo culturais) podem impor limitações à comunicação humana, com acometimento de órgãos ligados a função da fala e da escuta. Visando contornar tais limitações, campos diversos do conhecimento buscam se articular para desenvolver ferramentas na tecnologia assistiva no sentido de suprir alguma habilidade insuficiente, seja ela motora, comunicacional ou de aprendizado.

O grupo atendido pelas tecnologias assistivas (TA) envolve indivíduos em diferentes condições, como os acometidos por paralisia cerebral, autismo, afasia, esclerose lateral amiotrófica, sequelas de AVC, síndrome de down, traqueostomizados e traumas crânio-encefálico. Por sua aplicação, estas tecnologias podem ser utilizadas de modo temporário ou definitivo, com vistas à resolução em graus variáveis das necessidades apresentadas. Segundo a ISO 9999, uma das categorias da TA é a Comunicação Aumentativa e Alternativa (CAA), que apresenta vários métodos e ferramentas que possibilitam aumentar o repertório comunicacional, quando este se apresenta comprometido.

No presente estudo, a ferramenta abordada é um aplicativo de CAA chamado aBoard, disponível gratuitamente para dispositivos móveis com sistema operacional Android. $\mathrm{O}$ aplicativo (app) é uma ferramenta de construção de texto para pessoas não falantes que conta com diversos pictogramas que são elementos gráficos que representam um objeto, ação ou sentimento. Através de toques diretos em tela, o usuário seleciona entre um conjunto de pictogramas e o dispositivo o reproduz em áudio, o que permite inclusive construir frases. Eles são organizados em categorias para facilitar a localização, além de permitir a inclusão de novos símbolos e categorias com o site de suporte aBoard editor. Entretanto para este artigo será trabalhado a configuração inicial sem que seja feita nenhuma alteração.

O artigo tem como objetivo principal descrever, através de uma perspectiva semiótica, o modo como este app constrói seus sentidos para o usuário e permite ao não falante identificar o significado dos elementos visuais para se comunicar, analisando as categorias e pictogramas empregados pelo sistema. O trabalho aborda questões sobre a origem do aplicativo, apresenta os elementos da teoria semiótica que serve de moldura teórica e analisa a interface do aplicativo para, por fim, descrever os aspectos principais da operacionalidade deste tipo de tecnologia.

\section{METODOLOGIA}

O artigo é descritivo e parte da análise de um aplicativo de comunicação aumentativa e alternativa chamado aBoard. Ele foi desenvolvido por um grupo de pesquisa interdisciplinar chamado Assistive, fundado em 2014, no Centro de Informática (Cln) da Universidade Federal de Pernambuco (UFPE). Também faz parte do Centro Nacional de Referência em Tecnologia Assistiva (CNRTA) e recebe financiamento do Conselho Nacional de Desenvolvimento Científico e 
Tecnológico (CNPq) e da Coordenação de Aperfeiçoamento de Pessoal de Nível Superior (CAPES) (ASSISTIVE, 2017). O aplicativo faz o uso dos pictogramas da ARASAAC, criado por Sergio Palao, com a licença Creative Commons, que autoriza seu uso para fins não lucrativos.

A análise será feita levando em consideração o plano da expressão e o plano do conteúdo tendo como base a teoria Greimasiana. No primeiro plano serão considerados aspectos cromáticos, topológicos e eidéticos. Com essas três dimensões propostas por Greimas, busca-se sua relação com o plano do conteúdo e seu percurso gerativo de sentido. Os elementos a serem analisados serão os pictogramas e as categorias, o atalho de respostas rápidas e o modo como o sistema informa a localização atual do usuário e permite sua locomoção entre as telas.

\section{DESIGN, INTERFACE E COMUNICAÇÃO}

Dentro da CAA existem várias ferramentas, como as pranchas de comunicação simbólica e alfabética, os vocalizadores e os softwares para desktops e dispositivos móveis. No entanto as pranchas analógicas e os vocalizadores possuem limitações quanto ao número de símbolos expostos, além de que os vocalizadores ainda têm um elevado custo.

Em contrapartida, os softwares para dispositivos móveis se apresentam em forma de aplicativos, permitindo um maior número de pictogramas, algumas adaptações e possuem versões gratuitas. Ademais, diferente dos desktops, eles não ficam limitados a um único espaço, permitindo a comunicação em diferentes ambientes por conta da portabilidade dos aparelhos e também pela ubiquidade de acesso à rede. Desta forma, este é um sistema móvel que busca auxiliar o processo de comunicação de pessoas que possuam alguma deficiência ou inabilidade, sendo esta permanente ou temporária.

Em sua página de acesso, o app aBoard apresenta uma interface simples com a assinatura da marca e campos para que o usuário crie uma conta ou entre nela, exigindo acesso a internet ao primeiro momento. Essa conta também proporciona, caso mais de uma pessoa utilize o mesmo dispositivo, salvar as configurações e os pictogramas usados por cada usuário.

\section{OOoboord}

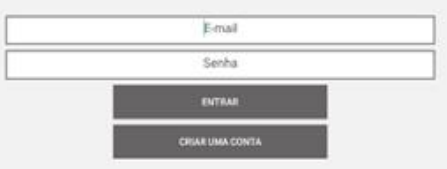

Fonte: ASSISTIVE, 2017 
As páginas de uso do aplicativo são divididas em duas partes: a superior possui atalhos como "RESPOSTAS RÁPIDAS", que são pictogramas pré-definidos, e "SUGESTÕES", que leva o usuário à categoria ou ao pictograma que logicamente corresponderia ao complemento do pictograma anterior. Por exemplo, se o usuário clica em "COMER" e depois em "SUGESTÕES", são exibidas a ele categorias de termos complementares, como "pessoas" e "comidas", que permitem detalhar com quem dividir uma refeição ou mesmo aquilo que se quer comer.

A parte superior também possui comandos como "FALAR", que reproduz todos os pictogramas selecionados na construção da frase, "LIMPAR", que exclui tudo para a construção de uma nova frase, os comandos "PRÓXIMO" e "ANTERIOR", que permitem avançar e voltar à aba de pictogramas e categorias subsequentes e, por fim, o comando "INÍCIO", que leva o usuário à página inicial. Essa parte também informa a localização da categoria acessada. A inferior mostra as categorias e pictogramas, além das linhas da rolagem horizontal quando existe mais conteúdo a ser visualizado.

Figura 2 - Página de uso inicial do aplicativo

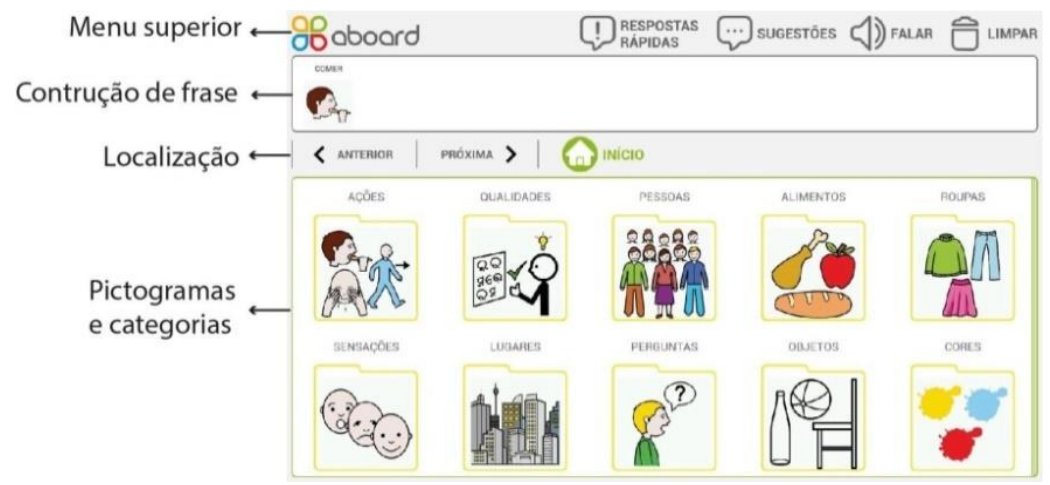

Fonte: arquivo pessoal.

Figura 3 - Página de uso

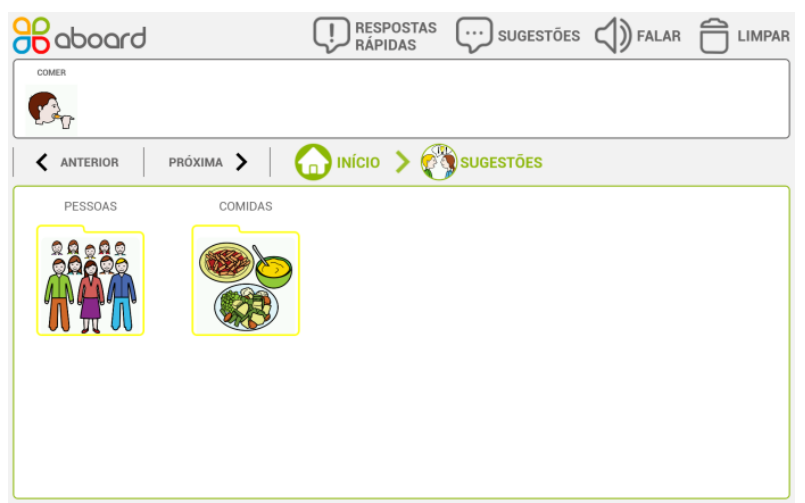

Fonte: arquivo pessoal. 
O atalho de "RESPOSTAS RÁPIDAS" é o único que altera a interface das páginas de uso do app, sendo o fundo dessaturado e uma página é jogada à sua frente com pictogramas em preto e branco. Para sair, deve-se clicar em algum pictograma ou fora da tela destacada, o que segue um padrão já consagrado de interfaces operadas pela tecnologia touchscreen.

Figura 4 - Atalho de respostas rápidas

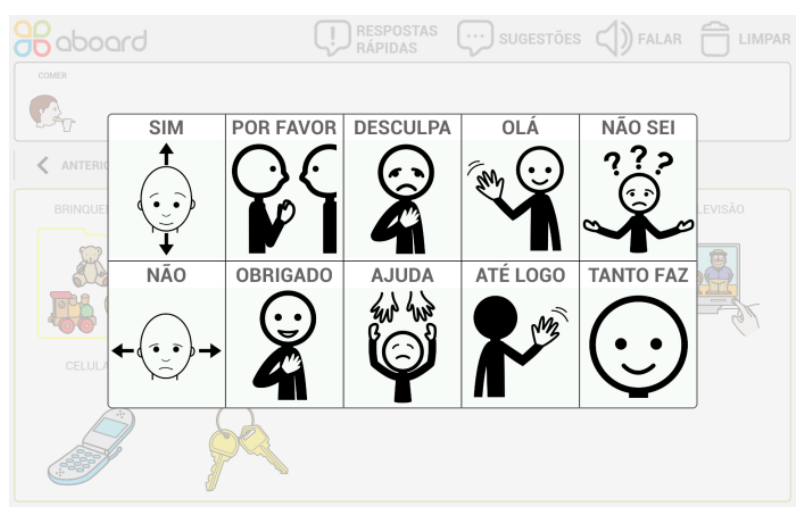

Fonte: arquivo pessoal.

\section{ANÁLISE SEMIÓTICA}

A semiótica Greimasiana se configurou inicialmente como uma semiótica dos textos. Para este campo teórico, um "texto" compõe uma unidade de significação podendo ser uma fala, um objeto, fotografia, filme, etc. que dá forma a um todo de sentido (SCOZ, MOTTA, 2016). A palavra texto deriva do latim e possui uma raiz etimológica comum com "tecer". Fiorin complementa dizendo que:

Da mesma forma que um tecido não é um amontoado desorganizado de fios, o texto não é um amontoado de frases, nem uma grande frase. Tem ele uma estrutura, que garante que o sentido seja apreendido em sua globalidade, que o significado de cada uma de suas partes dependa do todo (FIORIN, 1995, p. 165-166.)

Segundo o modelo semiótico greimasiano, um texto - qualquer que seja sua natureza pode ser descrito pela articulação entre duas dimensões indissociáveis: um plano da expressão e um plano do conteúdo. Em objetos verbais, como os textos de prosa e romance, a abordagem semiótica volta-se justamente ao plano do conteúdo, visto que a forma de manifestação (a expressão) não é decomponível em termos relevantes para a análise. Já em textos que utilizam outras formas de manifestação, como as visuais e outros textos estéticos (poema, balé, pintura etc.), a correlação entre o plano da expressão (formas, cores, etc.) e o conteúdo cria novas relações de sentido, contribuindo com a significação total do mesmo. Segundo Greimas, o plano do conteúdo dos textos se organiza em um percurso gerativo de sentido, que é constituído por três níveis, indo do mais abstrato e simples ao mais concreto e superficial, respectivamente 
identificados como fundamental, narrativo e discursivo. (LARA, 2011)

No nível fundamental de um texto são encontradas as oposições elementares da semântica de base, tendo como exemplo os contrários /vida/vs /morte/ e /ser/vs/ parecer/. Neste nível também são atribuídas valorizações, sendo o termo eufórico usado para valorização positiva e o termo disfórico para valorização negativa dos termos da estrutura (GREIMAS e COURTES, 2008).

Segundo Brito e Morato (2012), o nível narrativo "apresenta-se sob a forma de uma configuração narrativa abstrata em que os sujeitos se relacionam com objetos e outros sujeitos em busca de valores.". No caso do aplicativo, existe um usuário (destinatário) que a partir de uma relação contratual com o aBoard, inicia seu uso buscando seu objeto de valor que é a comunicação com o outro. Para isso, ele inicia a interação buscando dentro de várias categorias os pictogramas que necessita para a formação da frase, e a cada frase finalizada a conversa avança. Quando os pictogramas são selecionados na ordem errada ou não selecionados, o usuário recebe uma sanção negativa pelo não entendimento do outro sobre sua fala ou a não produção do áudio, mas quando dispostos de modo lógico, a sanção é positiva concretizando a comunicação.

O nível discursivo é aquele em que se revestem as estruturas narrativas abstratas de maior concretude, sendo igualmente o mais próximo da manifestação textual, conforme Brito e Morato (2012). Nesta etapa da análise, "examinam-se os temas, as figuras e as isotopias, elementos que concretizam as estruturas do nível anterior". Os temas procuram explicar a realidade a partir de termos abstratos. Já os figurativos criam um simulacro do mundo por termos concretos (FIORIN, 1999, 2006).

No aplicativo, através dos pictogramas, existe a representação de objetos e ações reais que aproxima o usuário da realidade. Sendo assim, estes elementos constroem a figuratização de ideias abstratas, permitindo ao usuário construir seus enunciados a partir de figuras organizadas linearmente e segundo uma intenção. Já a isotopia, segundo Fiorin (1999), é “... a recorrência de traços semânticos que determinam um dado plano de leitura", podendo assim um texto ter vários planos de leitura, mas uma prevalência a partir das repetições arranjadas pelo seu autor.

No plano da expressão, são trabalhadas três dimensões propostas por Greimas: a topológica, eidética e cromática. Mas é na sua junção com o plano do conteúdo que é feita a produção de sentido. Conforme Greimas e Courtés (2008), quando uma categoria do plano do conteúdo se correlaciona com outra no plano da expressão, tem-se uma relação semissimbólica. Um exemplo de tal esquema pode ser observado no arranjo plástico de certas obras do barroco. Nestes textos, podemos observar que a dimensão topológica (plano da expressão) organiza os termos superior e inferior, relacionando-os à oposição semântica de base /divindade/ vs /humanidade/(plano do conteúdo) .

Assim, a análise aqui proposta busca nas relações semissimbólicas a correlação entre o plano conteúdo e o plano da expressão, visando identificar os sentidos atribuídos aos elementos do aplicativo em questão e que facilitam sua utilização e viabilizam a comunicação. Os elementos a serem analisados são as categorias e pictogramas, o atalho de respostas rápidas e a localização do usuário e interação.

\subsection{Categoria e Pictogramas}

- Plano da expressão 
Os pictogramas foram organizados em categorias com o intuito de facilitar a sua localização. Quando o ícone da categoria é tocado, é aberta outra aba com os pictogramas que a compõem ou mais categorias. Como na categoria alimentos que exibe alguns pictogramas e as categorias de bebidas e comidas. Tanto os pictogramas como as categorias são demonstrados por um quadrado cinza claro com um elemento gráfico no seu interior e um título centralizado em sua parte superior.

A diferença de funcionalidade dos pictogramas para as categorias, é que, as categorias quando clicadas não adicionam nada a área de construção da frase e sim na barra de localização, segundo na dimensão cromática e eidética, elas apresentam uma borda amarela com forma de pasta, um ícone já conhecido por usuários de computador que indica um espaço onde se guarda e organiza arquivos. Além de que na dimensão topológica quando presente elas sempre aparecem na parte superior esquerda, antes dos pictogramas.

\section{- Plano Conteúdo}

Na divisão de "CATEGORIAS" e "PICTOGRAMAS" existe uma relação homologável aos conceitos de /grupo/ para a /unidade/, pois é o elemento único que permite a comunicação real através do som emitido pelo aplicativo e a sanção do usuário, sendo este o termo eufórico da oposição. Assim, no nível fundamental, tem-se o /Som/ vs /silêncio/ que confirma ou não a realização da operação.

\begin{tabular}{lll}
\hline & CADERNO & \\
\hline Plano da expressão & Pictograma & Categoria \\
\hline Topológica & Após categorias & Primeiro \\
Cromática & & Amarelo \\
Eidética & & Borda de pasta \\
\hline Plano conteúdo & & Silêncio \\
\hline Nível fundamental & Som & Grupo \\
\hline Nível discursivo & Unidade &
\end{tabular}

Tabela 1 - Plano da expressão e conteúdo: categorias e pictogramas

\subsection{Atalho de respostas rápidas}

- Plano da expressão 
$O$ atalho de respostas rápidas fica na parte superior, na aba de Menu. Ele pode ser acessado a qualquer momento e apresenta um total de dez pictogramas sendo: "SIM", "NÃO", "POR FAVOR", "OBRIGADO", "DESCULPA", "AJUDA", "OLÁ", "ATÉ LOGO", "NÃO SEI" e "TANTO FAZ". Depois de clicado, o atalho é fechado, e não ficam salvos na área de construção de frase. A tela que abre nesse atalho é disposta a frente da tela antes acessada, além da tela anterior ser dessaturada, o que traz uma diferenciação nas dimensões topológicas e cromáticas. Ainda no tocante aos aspectos cromáticos, os pictogramas dispostos por ela aparecem em preto e branco, 0 que reforça a diferenciação dos outros pictogramas.

De forma estética foi dado um tratamento diferente a estes elementos, destacando-os. 0 objetivo deste atalho é possibilitar respostas ou falas rápidas, selecionando pictogramas mais usados e disponibilizando-os em qualquer lugar do aplicativo. Entretanto, não é possível alterá-los.

\section{- Plano Conteúdo}

O atalho de respostas rápidas se apresenta como uma prancha fixa do aplicativo, estabelecendo uma relação de /dinamicidade/vs /estaticidade/ (nível fundamental) da prancha em comparação com as outras telas. No nível discursivo, o percurso sai do modo /alterável/ para o /fixo/. Entretanto, no que diz respeito à construção da fala, o nível fundamental estabelece uma relação de /ágil/ vs/ lento/. O uso ou não deste atalho varia da necessidade no processo de comunicação, sendo que este não é usado na construção das frases.

\begin{tabular}{lll}
\hline Plano da expressão & Aplicativo & Tela atalho \\
\hline Topológica & Atrás & A frente \\
Cromática & Dessaturado & Preto e branco \\
Eidética & & Retângulo \\
& & \\
\hline Plano conteúdo & & \\
\hline Nível Fundamental & Dinamicidade & Estaticidade \\
Nível discursivo & Alterável & Fixo \\
\hline \multicolumn{2}{l}{ Construção da frase } & \\
\hline Nível Fundamental & Lento & Ágil \\
\hline
\end{tabular}

Tabela 2 - Plano da expressão e conteúdo: atalho de respostas rápidas

\subsection{Localização do usuário e interação}

- Plano da expressão

O aplicativo utiliza diversos meios para orientar o usuário em sua localização. Na parte superior do aplicativo, na área de localização, é mostrado em que categoria o usuário está e qual o caminho percorrido até ele, sempre começando com o início, para uma categoria e para a próxima sucessivamente. Essa parte é mostrada em verde com o símbolo da categoria e o seu nome 
seguido por uma seta ">", seguida pela próxima categoria, sua categoria atual é a última da sequência. Todos os nomes são clicáveis e levam o usuário à categoria selecionada.

Já as setas em cinza com os nomes "PRÓXIMO" e "ANTERIOR" permitem a locomoção entre as páginas de pictogramas e categorias abaixo, mas também é possível movê-las com o passar do dedo para esquerda ou direita fazendo um movimento horizontal na tela. Entretanto, nem todas as áreas possuem mais de uma página, para isso o aplicativo utiliza uma indicação de três linhas verdes na vertical (imitando a sobreposição de folhas), permitindo identificar que se houver mais conteúdo à direita as linhas são mostradas nesta região, enquanto que quando há conteúdo na esquerda e direita são mostrados em ambos os lados.

\section{- Plano Conteúdo}

A seta utilizada no aplicativo tem a representação do maior para o menor indicando uma categoria maior e mais abrangente até algo mais específico. O modo de organização do aplicativo sempre segue da esquerda para a direita, o que dialoga com o modo de leitura ocidental e sua localização segue o mesmo parâmetro. Esta disposição ajuda a visualizar e a localizar algo específico, pois sem essa categorização o usuário estaria perdido em vários pictogramas. Existe então, no nível fundamental, um sentido de /ordem/vs/caos/ e o percurso sai da /aleatoriedade/ para a /categorização/ no nível discursivo, sendo esta ordem necessária para que o usuário utilize o aplicativo.

Quanto à indicação de mais conteúdo em uma mesma área, os artefatos digitais já vêm criando artifícios para isso, o que não foi diferente no aplicativo que estabeleceu que as três linhas verdes fizessem essa indicação. E para o acesso a esse conteúdo oculto existem dois meios, o primeiro pelos botões de "< ANTERIOR" e "PRÓXIMO >" e o segundo com a movimentação horizontal do dedo sendo o "PRÓXIMO" da direita para a esquerda e o "ANTERIOR" o oposto. Sendo o nível discursivo /direita/ para a /esquerda/ que dialoga com o /ir/ do nível fundamental e o oposto para o/voltar/

\begin{tabular}{|c|c|c|}
\hline Plano da expressão & Sistema de localização & Inexistência \\
\hline Topológica & Esquerda para direita & \\
\hline Cromática & Verde & \\
\hline Eidética & Seta ">" & \\
\hline \multicolumn{3}{|c|}{ Interação na rolagem: } \\
\hline Topológica & Direita & Esquerda \\
\hline \multicolumn{3}{|l|}{ Plano conteúdo } \\
\hline Nível fundamental & Ordem & Caos \\
\hline Nível discursivo & Categoriza & Mistura \\
\hline \multicolumn{3}{|l|}{ Interação na rolagem: } \\
\hline Nível fundamental & Ir & Voltar \\
\hline Nível discursivo & Direita & Esquerda \\
\hline
\end{tabular}


Tabela 3 - Plano da expressão e conteúdo: Localização do usuário e interação

\section{CONSIDERAÇÕES FINAIS}

Tendo como objetivo principal a análise dos meios de interação, interface e organização do aplicativo de CAA, aBoard, pode-se observar que, a partir do uso de ferramenta de análise semiótica, o princípio geral de construção da interface do aplicativo é a unidade dos elementos, que se pode correlacionar à ideia de consistência preconizada no desenvolvimento dos artefatos interativos. Entretanto, durante a análise, pode-se constatar que os elementos de ordem e categorização - engendrados no interior do aplicativo e operados na interação - são os que permitem ao usuário entender, localizar e por fim, selecionar o pictograma desejado, além de que é a dinamicidade que amplia seu repertório e lhe confere autonomia. Há, pelo percurso gerativo, a manipulação pela tentação que dá ao usuário sua sanção caso exista a interação, sendo uma competência - a correta interpretação dos elementos visuais - necessária à construção frasal e à dinâmica da comunicação eficiente.

Por esta proposta metodológica, observou-se que o princípio da articulação entre plano da expressão e do conteúdo apresenta uma importante e promissora perspectiva de estudo para interação, visto que o esclarecimento da relação de solidariedade que se estabelece entre eles permite entender a dinâmica de leitura dos elementos constituintes do texto visual e interativo. Para este trabalho, e a partir do objetivo inicialmente proposto, a análise privilegiou uma seleção de alguns aspectos do aplicativo, o que ajuda a explicar em linhas gerais seu funcionamento e explicita a maneira como os usuários desempenham suas tomadas de decisão e operam as funcionalidades da tecnologia assistiva. Pelo estabelecimento de categorias e pela ordenação, o processo de comunicação aumentativa e alternativa se torna mais acessível e ajuda na integração do usuário na sociedade através da comunicação.

\section{Referências}

ASSISTIVE, Inovando a maneira de comunicar! Disponível em: http://assistive.cin.ufpe.br/pt/sobre Acessado em 20 jan. 2018.

BRITO, Clebson; MORATO, Elisson. O verbal e o visual na construção de sentidos: leitura e lições de textos sincréticos sobre copa do mundo de futebol. Revista Inventário, Bahia, n. 11, jul./dez. 2012. Disponível em: . Acesso em 10 out. 2015.

FIORIN, J. L. A noção de texto na semiótica. In: Revista Organon, UFRGS: Porto Alegre, v. 9, n. 26, 1995.

FIORIN, José Luiz. Elementos de análise do discurso. São Paulo: Contexto, 2006.

FIORIN, José Luiz. Sendas e Veredas da Semiótica Narrativa e Discursiva. DELTA. vol.15 n.1 São

Paulo Feb./July $1999 . \quad$ Disponível em:
http://www.scielo.br/scielo.php?script=sci_arttext\&pid=S0102-44501999000100009 acessado: 18 jan. 2018 
GREIMAS, Algirdas Julien; COURTÉS, Joseph. Dicionário de semiótica. São Paulo: Contexto, 2008

ISO 9999. Assistive products for persons with disability - Classification and terminology. Fourth edition. 2007. International Standard.

LARA, Glaucia Muniz Proença. A imagem como objeto de ensino. Cadernos de semiótica aplicada, vol. 9 n.1 julho 2011. Disponível em: http://seer.fclar.unesp.br/casa/article/viewFile/4423/3917. Acessado em: 20 jan. 2018.

SCÓZ, Murilo; MOTTA, Rafael G. Sociossemiótica para o design de interação. In: SCÓZ, Murilo; VANDESEN, Monique; RAMALHO e OLIVEIRA, Sandra. (orgs.). Proposições interativas: modos de produzir sentidos. Florianópolis: UDESC, 2016. (pp. 29-63). 